\title{
Equipping First Aid Learners to Respond in Fragile Environments
}

\author{
Ellen Gordon, Thomas Wilp, Emily Oliver
}

As posited by the Chain of Survival Behaviours (IFRC, 2016), the purpose of first aid education goes beyond skill acquisition. It seeks to equip and empower people to respond to situations requiring first aid outside of a learning environment, where an educator is unlikely to be present nor a first aid kit at hand. Situations may be fragile and require learners to think critically and act creatively in order to deliver first aid. The British Red Cross (BRC) and International Committee of the Red Cross (ICRC) are currently collaborating on empirical research to expand the evidence base for effective first aid education in fragile environments. 'Fragility' typically refers to limited/weakened state capacity to provide basic services in a specific scenario (OECD, 2006). The purpose of the research is to explore the application of the pedagogical theory presented in the International First Aid and Resuscitation Guidelines (IFRC, 2016) which advocates for contextually relevant education which focuses on the needs of the learner.

\section{Conference engagement}

Our session explored how environments can be potentially limiting factors in first aid situations. This included an exploration of what makes a situation fragile, from entrenched fragility in areas of armed conflict, to situations made suddenly fragile by remote location or over-stretched healthcare services. The aim was to enable participants to discuss pedagogical approaches to equip learners to deal with and respond to these types of situations.

The session began with an explanation of the research mentioned above. The main activity centered on the discussion of approaches to equipping learners to respond to four, increasingly challenging and fragile first aid scenarios. Participants discussed each scenario in turn, identifying the limits imposed by the context, and what the learner would be required to do in order to be able to give first aid. Once these had been identified, the discussion progressed to pedagogical approaches which could equip learners to respond to that scenario. These ranged from role playing activities where learners use everyday items instead of a first aid kit, to peer learning and feedback through sharing ideas.

Two main implications arose from this session. The first is the idea that to be truly effective, first aid education must develop learners into potential responders. In order to do this, first aid education must take into account the disparity between learning and real-life contexts, and ensure learners are equipped to respond to a range of situations, particularly ones that may be fragile. The second implication challenges the collective understanding of 'fragile' environments. Entrenched and sudden fragility both require responders to think critically and act creatively. Sudden fragility can occur anywhere, a reality that should be accounted for in first aid education. 
Conference Abstract

International First Aid Education Conference, 22-25 April 2018

\section{References}

International Federation of the Red Cross Red Crescent, (2016) International First Aid and Resuscitation Guidelines, Geneva.

Organisation for Economic Development, (2006) DAC Guidelines and Reference Series Applying Strategic Environmental Assessment: Good Practice Guidance for Development Co-operation, Paris. 
Conference Abstract

International First Aid Education Conference, 22-25 April 2018 